\title{
Detection of antibodies to ovine herpesvirus-2 interleukin-10 homologue in sheep-associated malignant catarrhal fever
}

\section{${ }^{\wedge}$ Cissell, Robin L, "Shahira Abdel Wahab, +Robert L. Donnell, and *Stephen A. Kania}

University of Tennessee Veterinary Teaching Hospital, Knoxville. *Department of Comparative Medicine, +Department of Pathobiology, ${ }^{\wedge}$ Comparative and Experimental Medicine Program, ${ }^{\#}$ Department of Virology, Faculty of Veterinary Medicine, Suez Canal University, Ismailia, Egypt.

\begin{abstract}
:
Interleukin-10 (IL-10) interferes with monocyte and macrophage activation of Th1 helper lymphocyte production of nitric oxide and synthesis of various inflammatory mediators. An IL-10 homologue (vIL-10) is produced by several herpes viruses and is hypothesized to help the virus down regulate, and thus evade, host immune responses. The gammaherpes rhadinovirus Ovine herpesvirus-2 (OvHV-2) encodes an IL-10 like molecule highly homologous to mammalian IL-10. This virus causes sheep-associated malignant catarrhal fever (MCF), the most common form of MCF in the United States. MCF is a lymphoproliferative and inflammatory syndrome that has delayed clinical presentation hypothesized to be influenced by the production of vIL-10. For this study, the gene encoding vIL-10, Ov2.5 ORF, was amplified by PCR, cloned, sequenced, and a predicted 30 amino acid segment from the amino terminus synthesized. This synthetic peptide was used to develop a novel direct enzyme-linked immunosorbant assay (ELISA) to detect isotype-specific antibodies to OvHV-2 vIL-10. Work to date indicates that lambs do not have detectable levels of maternally derived antibody to vIL-10 during the first few weeks of age. Ewes, which are refractory to clinical infection, generally have high levels of antibody to vIL10. A weak correlation exists between the vIL-10 ELISA and a commercially available competitive-inhibition ELISA (cELISA). We believe the vIL-10 ELISA will refine the ability to identify ruminants exposed to sheepassociated MCF, provide an important tool for determining the role of vIL10 in disease pathogenesis, and may contribute toward the development of a new vaccine strategy for the control of malignant catarrhal fever.
\end{abstract}

\section{Introduction}

Interleukin-10 (IL-10), or cytokine synthesis inhibitory factor (CSIF), suppresses the immune system. It interferes with monocyte and macrophage activation of Th1 helper lymphocyte production of nitric oxide and synthesis of various 
inflammatory mediators (de Vries, 1995). These mediators of inflammation include IL-12 and interferon gamma. The first herpesvirus-encoded homologue of IL-10 (vIL-10) was identified in the gammaherpesvirus Epstein-Barr virus (Nicholas, 2005). Studies in mice demonstrate that vIL-10 has in vivo cell-deactivating activity (Suzuki, et al, 1995). An IL-10 homologue has since been identified in other herpes viruses, including cytomegalovirus, and equine herpes virus 2, (Engelberg et al, 2007; Rode et al, 1993). This cytokine homologue is hypothesized to help viruses down regulate, and thus evade, host immune responses by mimicking mammalian IL-10 (Rode et al, 1993). This process may help the virus establish infection in the host. Similar to the parapoxvirus Orf virus, the gammaherpes rhadinovirus Ovine herpesvirus-2 (OvHV-2) encodes an IL-10 like molecule highly homologous to ovine IL-10 (Fleming, et al, 2000; Hart et al, 2007). OvHV-2 causes sheep-associated malignant catarrhal fever (MCF), the most common form of MCF in the United States. Sheep-associated MCF infects many ruminant animal species including deer and cattle, and is particularly virulent in the American bison. The disease caused by this virus is a lymphoproliferative and inflammatory syndrome which has delayed clinical presentation. Thus
vIL-10 may suppress the host immune response long enough for the virus to become established and delay the onset of symptoms.

Currently there is no vaccine available for prevention of this disease, and little is known regarding its pathogenesis. We believe the vIL-10 synthetic peptide enzyme-linked immunosorbant assay (ELISA) will help elucidate the natural antibody response to OvHV-2 vIL-10 in ruminants exposed to sheep-associated MCF. This information will be important for determining the role of vIL-10 in disease pathogenesis and the ability of the host to potentially neutralize this viral cytokine. This information could contribute toward the development of a new vaccine strategy for the control of malignant catarrhal fever and help to determine the mechanism of disease in ruminant species with a high mortality rate for OvHV-2 infection.

\section{Materials and Methods}

\section{Samples:}

- Blood collected from sheep ranging in age from approximately 2 months to 13 years was placed into sodium heparin tubes, centrifuged, and plasma removed.

- Sheep were located in four geographically distinct regions of East Tennessee, USA (Figure 1), with no transfer of sheep between locations.

\section{Peptide Preparation:}


- The gene encoding vIL-10, Ov2.5 ORF, was amplified by PCR using previously described methods (Virus Genes, 2006).

- The product was cloned, and then sequenced (University of Tennessee sequencing facilities).

- The predicted amino acid sequence was aligned with sequences deposited in public databases using protein blast. A portion from the amino terminus, with minimal amino acids shared with ovine and bovine IL-10, was identified.

- A 30 amino acid segment from the amino terminus was synthesized (Genscript, Scotch Plains, NJ).

- This peptide was used as the antigen in a direct ELISA to detect $\mathrm{IgG}$ antibodies reactive with OvHV-2 vIL-10.

\section{Peptide ELISA:}

- Sheep plasma was utilized as the primary antibody at a 1:25 dilution $(\mathrm{n}=45)$.

- Rabbit anti-sheep IgG (gamma chain specific) labeled with horseradish peroxidase (Kirkegaard and Perry Labs, Gaithersburg, MD) was utilized as the secondary antibody.

- TMB substrate was added to detect bound secondary antibody (Peirce, Rockford, IL )

- The results were read at $450 \mathrm{~nm}$, after 20-30 minutes of development.

\section{Comparison ELISA:}

A commercial Malignant Catarrhal Fever Virus cELISA was performed using sheep plasma from the peptide ELISA according to the manufacturer's instructions (VMRD, Pullman WA, USA)

- Sheep plasma were selected based on results of the peptide ELISA, with 13 samples chosen with strong reactivity (OD $\geq 0.8$ ), 20 samples chosen with moderate reactivity $(0.8<\mathrm{OD}>0.3)$, and 13 samples chosen with little to no reactivity $(\mathrm{OD}<0.3)$ (n total $=45)$.

\section{Objectives}

- To determine the amino acid sequence of the OvHV-2 vIL-10 homologue in regional samples

- To obtain a synthetic peptide corresponding to a section of OvHV-2 vIL-10 potentially immunogenic in sheep and other susceptible animals.

- To determine if antibody reactive with OvHV-2 vIL-10 occurs in sheep naturally infected with OnHV-2.

\section{Results}

The amino acid sequence of the OvHV-2 vIL-10 gene from sheep in Tennessee, USA is homologous to the same gene reported by researchers working in the UK. and in Pullman, Washington (data not shown).

Our results indicate that lambs, which are normally refractory to infection, do not have detectable levels of IgG to vIL-10 during the first few weeks of age. Ewes, which are susceptible to clinical infection, generally have moderate to high levels of antibody to vIL-10. A weak correlation exists between the vIL-10 ELISA and a commercially available 
competitive-inhibition ELISA (2 ewes). Of the 12 samples which (cELISA).

Anti-viral IL-10 antibodies were exhibited little to no antibody: 3 were lambs $\sim 5$ months or younger, found in moderate to high levels in 33 of 45 sheep (73\%) (Figure 3). 4 were $\sim 1$ year, 1 was $\sim 2$ years of age, 1 was $\sim 3$, another was $\sim 5$, and Immunoreactivity was detected across several breeds of sheep, from samples taken from distinct geographical regions in East Tennessee. The youngest of these sheep included one lamb less than 3 months, and three $\sim 6-7$ months of age. The oldest were 8 years of age the oldest was $\sim 11$. Of the sheep plasma tested with the MCF cELISA, 39 of 45 were considered to be positive (inhibition of greater than 25\%)(Figure 4). Negative samples included 2 lambs $\sim 6-7$ months of age and 4 ewes $\sim 1$ year of age.

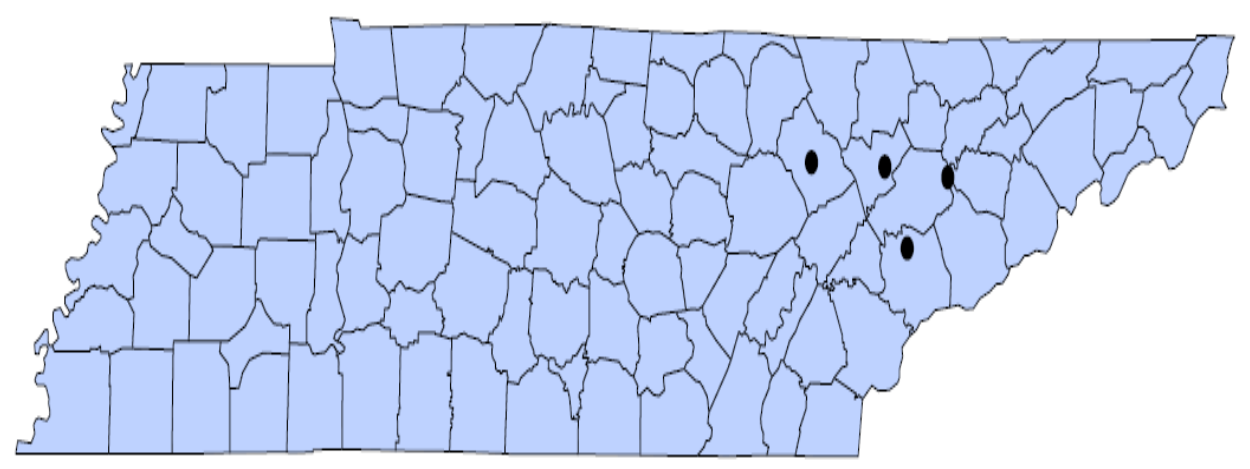

Figure 1: Distribution of sheep collection sights, State of Tennessee, eastern region, USA. One inch $(2.5 \mathrm{~cm})$ equals 50 miles $(80 \mathrm{~km})$. 


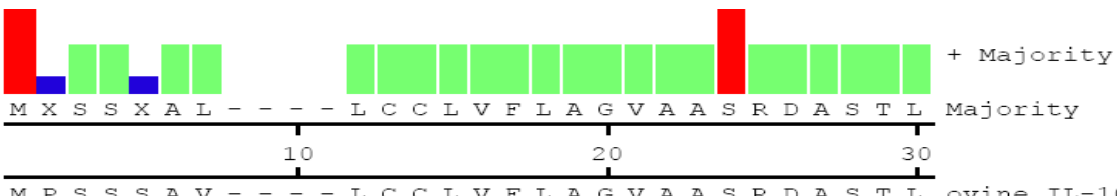

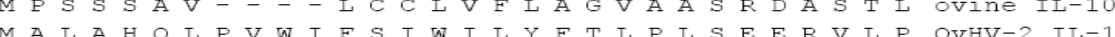
MHSS-AL - - ICCIVEIAGVA A S D A S T I bovine IL-10
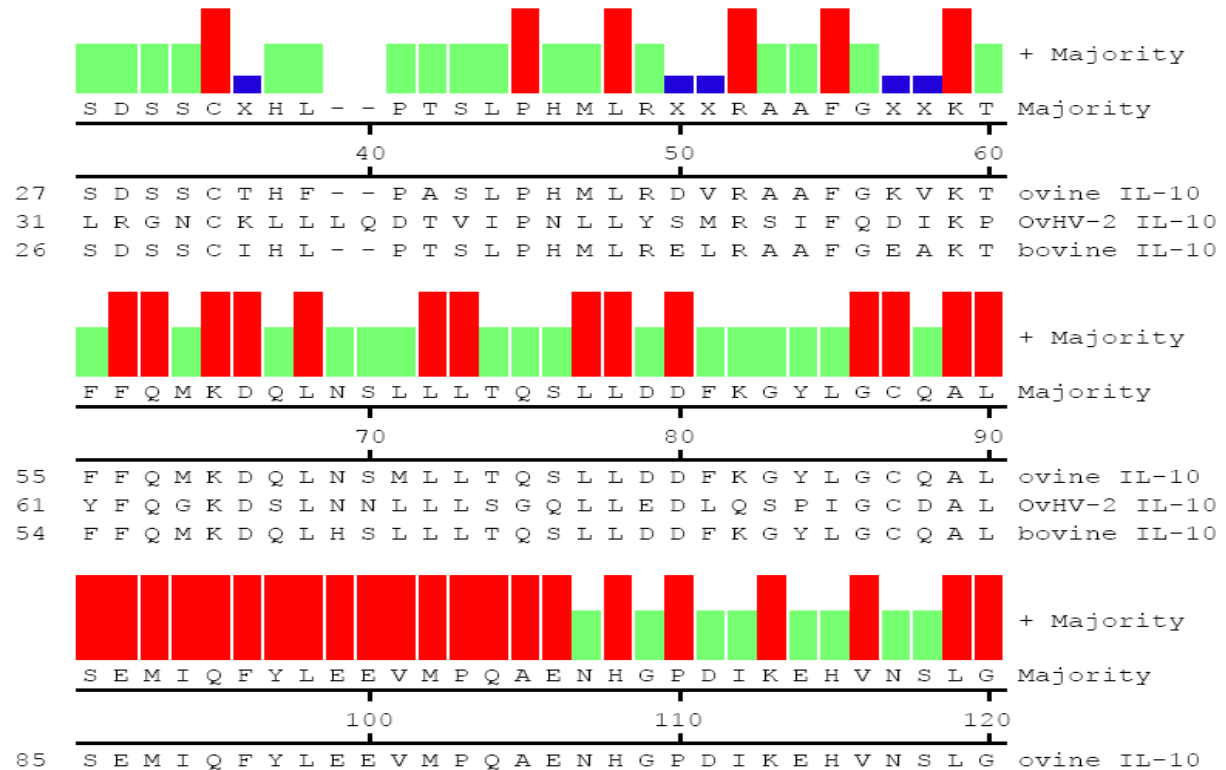

$S E M I Q F Y I E E V M P Q A E I H H R K H K N S V M Q I G$ OVHV-2 IL-10

$S E M I Q F Y I E E V P Q A E N H G P D I K E H V N S I G$ bovine IL-10

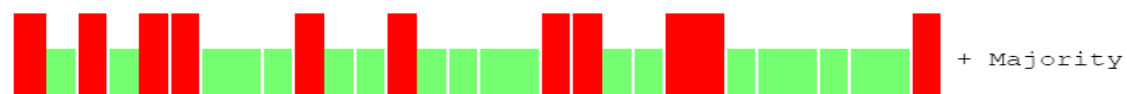

E K I K T I R I R I R R C H R F L P C E N K S K A V E K V K Majority

130

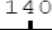

115 E K I K T L R I R I R R C H R F I P C E N K S K A V E O V K ovine IL-10

$121 \mathrm{E} T \mathrm{~T} H \mathrm{~T} I \mathrm{I} Q \mathrm{~L} Q \mathrm{E} C \mathrm{~T}$ A I F $\mathrm{P} C \mathrm{~K}$ H K S L G A $Q \mathrm{~K} I \mathrm{~K}$ OVHV-2 IL-1O

$114 \mathrm{EK}$ L K T L R I R L R C H R F I P E N K S K A V E K V K bovine IL-10

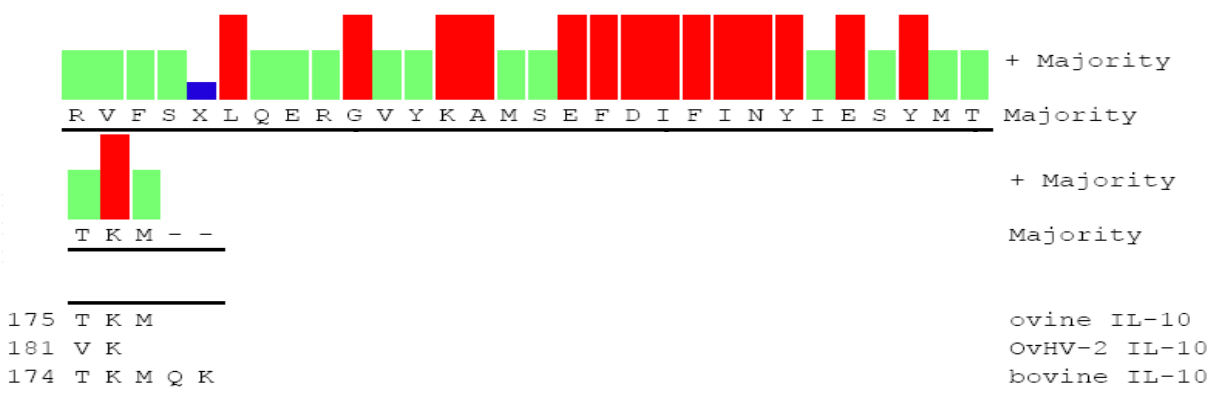

Figure 2: Alignment of bovine, ovine, and OvHV-2 viral IL-10 using ClustalV. Synthetic peptide portion underlined in blue. 


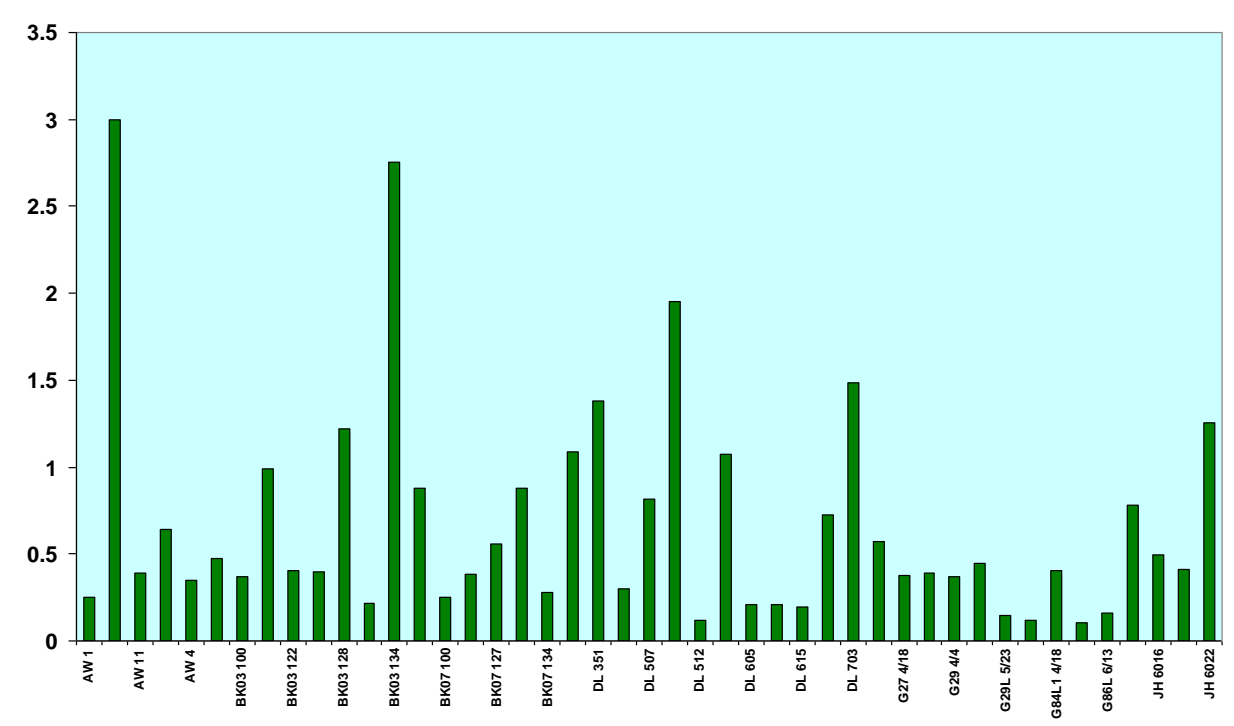

Figure 3: Results of vIL-10 ELISA. X axis= sample ID; $Y$ axis=optimum density. Results read at $450 \mathrm{~nm}$

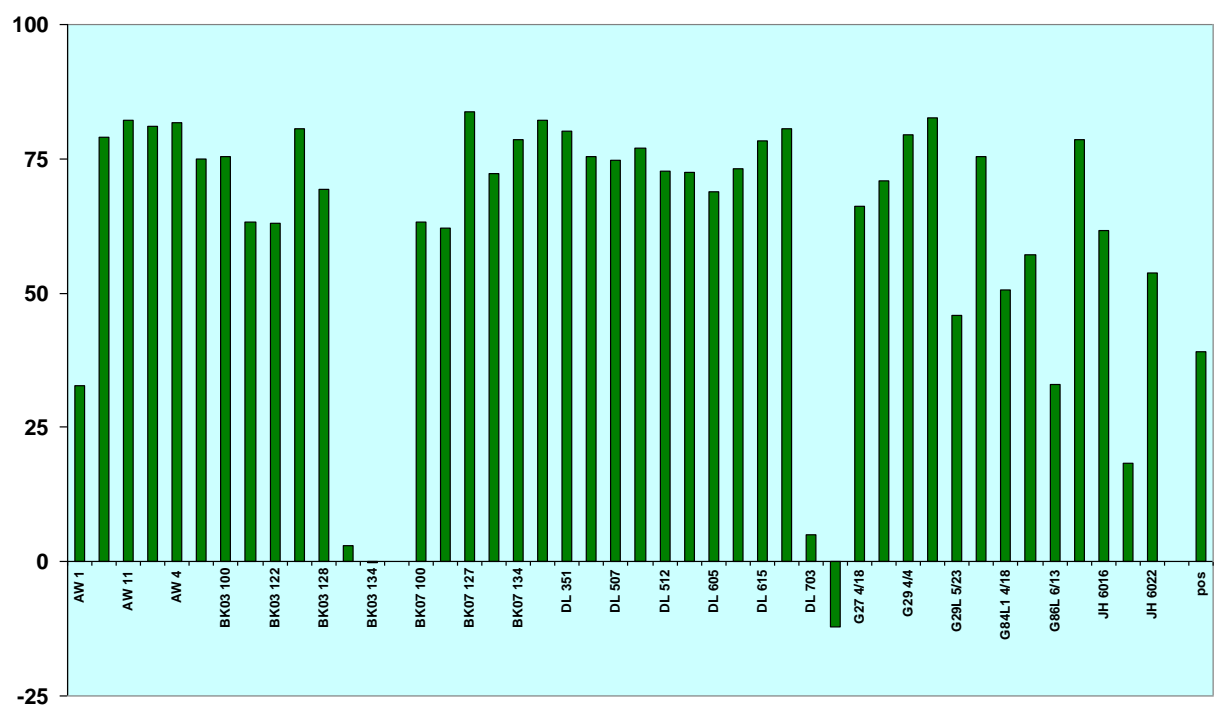

Figure 4: Results of MCF cELISA (VMRD). X axis $=$ sample ID; $Y$ axis $=\%$ inhibition. Results read at $450 \mathrm{~nm}$ 


\section{Discussion}

Maternal anti-MCFV antibody has been shown to be detectable by competitive inhibition ELISA for about 10 +/- 3 weeks (Li et al, 1995). In the current study, antivIL-10 IgG antibody was not detectable in young lambs, approximately 6-10 weeks of age (exact date of parturition unknown). This implies that antibodies to this homologue may not develop upon initial infection, but may occur later in life upon prolonged or recurrent infection with the OvHV-2. Adult ewes display varying levels of antibody to vIL-10, and in this study have shown high levels of anti-vIL-10 antibodies, while displaying no detectable antibody in the competitive ELISA. The identification of an immunogenic region of OvHV-2 vIL-10 opens the door to future research, such as determining the role antibodies against this viral cytokine may play in neutralizing the immune modulatory role of this protein. Furthermore, the immunogenicity of OvHV-2 vIL-10 in cattle and bison, which have high morbidity and mortality, may be explored. Finally, OvHV-2 vIL-10 may be examined as a vaccine candidate especially for use in cattle and bison.

\section{References}

Altshul SF, W Gish, Miller W, Myers EW, and Lipman DJ. (1990): Basic alignment search tool. Journal of Molecular Biology 215:403-410

de Vries, JH. 1995. Immunosuppressive and antiinflammatory properties of interleukin-10. Annals of Medicine 27(5):537-541.

Engelberg NC, DiRita V, Dermody TS (Eds). (2007):

Schaechter's Mechanisms of Microbial Disease forth Ed. Lippencott Williams and Wilkins. Baltimore MD. 418-419.

Fleming SB, Haig DM, Nettleton P, Reid HW, McCaughan CA, Wise LM, and Mercer AA. (2000): Sequence and functional analysis of a homolog of interleukin-10 encoded by the parapoxvirus orf virus. Virus Genes 21(1/2): 85-95.

Hart J, M Ackermann, G Jayawardane, G Russell, DM Haig, H Reid, and JP Stewart. (2007): Complete sequence and analysis of the ovine herpesvirus 2 genome. Journal of General Virology 88: 28-39.

Li H, Shen DT, O'Toole D, Knowles DP, Gorham JR, and Crawford TB. (1995): Investigation of sheep-associated malignant catarrhal fever virus infection in ruminants by PCR and competitive inhibition enzymelinked immunosorbent assay. Journal of Clinical Microbiology 33(8):2048-2053.

Nicholas, J. (2005): Human gammaherpesvirus cytokines and chemokine receptors. Journal of 
Interferon and Cytokine Research 25:373-383.

Rode HJ, Janssen W, RosenWolff A, Bugert JJ, Thein P, Becker Y, and Darai G. (1993): The Genome of Equine Herpesvirus Type 2 harbors an Interleukin 10 (IL10)-Like Gene. Virus Genes 7(1):111-116.
Suzuki T, Tahara H, Narula S, Moore KW, Robbins PD, and Lotze MT. (1995): Viral interleukin-10 (IL-10), the human herpes virus 4 cellular IL-10 homologue, induces local anergy to allogenic and syngeneic tumors. Journal of Experimental Medicine 182:477-486.

\section{الكثف عن الأجسام المضادة لمرض حمى الحمرة الخبيثية (عترة هربس الأغنام 2) انترلوكين 10 المناظر في الأغنام}

انترلوكين · 1 (IL-10) يتداخل مع تنتيط خلايا الوحيدات وخلايا البلاعم الخاص بانتاج الخلايا

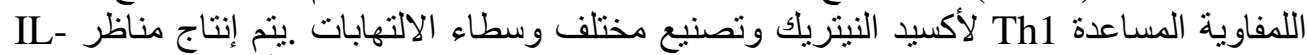

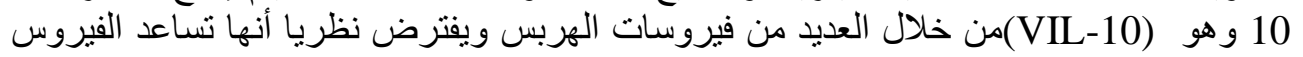

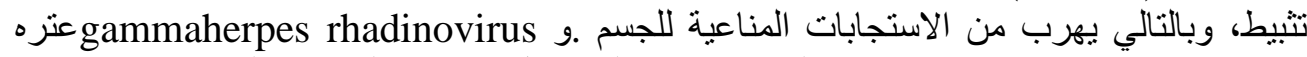

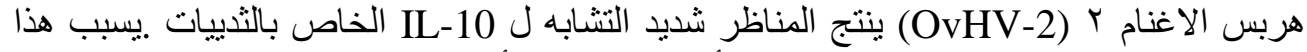

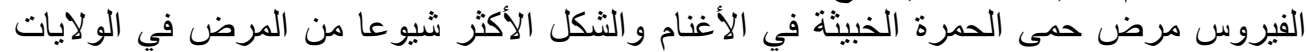

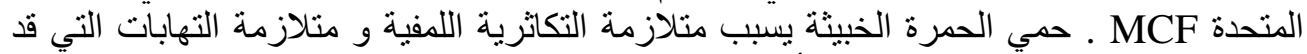
تأخر الأعراض الإكلينيكية المفترض ثأثاثٔرها بإنتاج

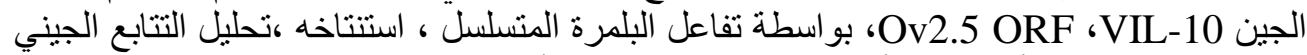

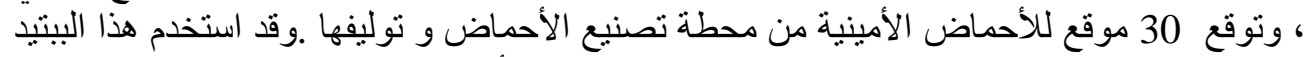

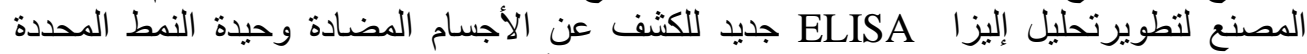

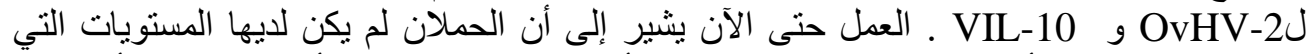

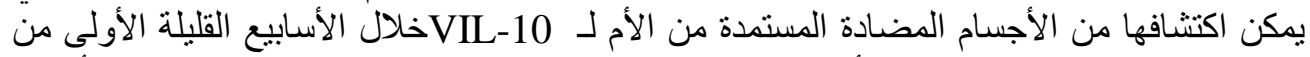

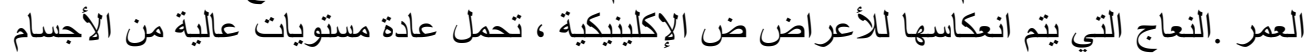

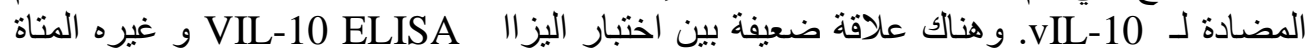

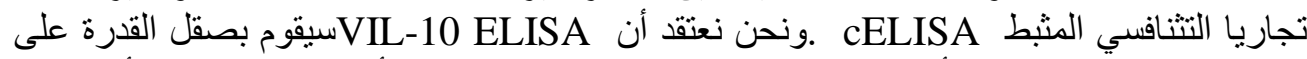

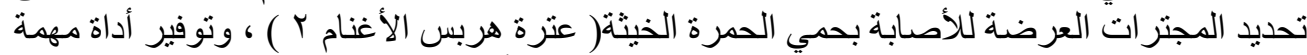
لتحديد دور جديد للسيطرة على حمي الحمرة الخبيثة. 